\title{
Stop Propagating Disaster Myths
}

\section{Dr. Claude de Ville de Goyet, MD}

\author{
Dr. Claude de Ville de Goyet is the Chief of \\ the Emergency Preparedness and Disaster \\ Relief Coordination Program of the Pan \\ American Health Organization, Regional \\ Office for the Americas of the World Health \\ Organization. \\ Correspondence: \\ 523 Twenty-third Street, N. W. \\ Washington, D.C. 20037 USA \\ disaster@paho.org
}

Keywords: bodies of dead; communicable disease; disaster; disaster managers; donors; earthquake; myths; Pan American Health Organization; realities; resources; responses; safety; water
The international responses to the tragic earthquake in Turkey highlight the need to reassess the myths and realities surrounding disasters, and to find ways to stop these destructive tales. The myth that dead bodies cause a major risk of disease, as reiterated in all large natural disasters from the earthquake in Managua, Nicaragua (1972) to Hurricane Mitch, and now to the Turkish earthquake, is just that, a myth. The bodies of victims from earthquakes or other natural disasters do not present a public health risk of cholera, typhoid fever, or other plagues mentioned by misinformed medical doctors. In fact, the few occasional carriers of those communicable diseases who were unfortunate victims of the disaster are a far lesser threat to the public than they were while alive. Often overlooked is the unintended social consequence of the precipitous and unceremonious disposal of corpses. It constitutes just one more severe blow to the affected population, depriving them of their human right to honor the dead with a proper identification and burial. The legal and financial consequences of the lack of a death certificate will add to the suffering of the survivors for years to come. Moreover, focusing on the summary disposal, superficial "disinfection" with lime, mass burial, or cremation of corpses requires important human and material resources that instead should be allocated to those who survived and remain in critical condition.

Our experience in the aftermath of the earthquake in Mexico City showed that health authorities and the media can work together to inform the public, make possible the identification of the deceased, and the return of the bodies to the families in a climate free of unfounded fears of epidemics.

The myth that the affected local population is helplessly waiting for the Western world to save it also is false, especially in countries with a large but unevenly distributed - medical population. In fact, only a handful of survivors owe their lives to foreign teams. Most survivors owe their lives to neighbors and local authorities. When foreign medical teams arrive, most of the physically accessible injured have received some medical attention. Western medical teams are not necessarily most appropriate to the local conditions.

As a professional disaster manager, the press coverage of the Turkey earthquake leaves me with a sense of dejà vu: "international rescue teams rushing in are made to look as though they are saving victims neglected by incompetent or corrupt local authorities". We saw the same cliche after major earthquakes and hurricanes in the countries served by the Pan American Health Organization (PAHO) in this western hemisphere.

Disaster-stricken countries appreciate external assistance that can do a lot of good when directed to real problems. Unfortunately, too much of the assistance is directed to non-issues or myths. For example, a common myth is that any kind of international assistance is needed, and it's needed now, while our experience shows that a hasty response that is not based on familiarity with local conditions and meant to complement the national efforts only contributes to the chaos. Often, it is better to wait until genuine needs have been assessed. Many also believe that disasters bring out the worst in human behavior, but the truth is that while isolated cases of antisocial behavior exist, the majority of people respond spontaneously and generously.

The myth that the affected population is too shocked and helpless to take responsibility for their own survival is 
superceded by the reality that on the contrary, many find new strength during an emergency, as evidenced by the thousands of volunteers who spontaneously united to sift through the rubble in search of victims after the 1985 Mexico City earthquake or the recent ones in Turkey. Perhaps this cross-cultural dedication to the common good of so many local volunteers and institutions, without red tape or petty institutional turf fights, keeps alive our faith in humankind and society.

The myth that things go back to normal within a few weeks is especially pernicious. The truth is that the effects of a disaster last a long time. Disaster-affected countries deplete many of their financial and material resources in the immediate post-impact phase. The bulk of the need for external assistance is for the restoration of normal primary health care services, water systems, housing, and income-producing work. Social and mental health problems will appear when the acute crisis has subsided and the victims feel (and often are) abandoned to their own means. Successful relief programs gear their operations to the fact that international interest wanes as needs and shortages become more pressing.

Natural disasters such as the tragic recent Turkey earthquake do not result in imported diseases that are not already present in the affected area, and they do not provoke secondary disasters through outbreaks of communicable diseases. Proper resumption of public health services, such as immunization and sanitation measures, control and disposal of waste, and special attention to water quality and food safety, will ensure the safety of the population and of the relief workers.

It is essential that the press and the donor community be aware of what is good practice and malpractice in public health emergency management. Past suddenimpact natural disasters in the Americas and elsewhere have shown the need for international contributions in cash and not in kind. This ensures that allocation of resources is field-driven by evidence of what is needed on-site. The population in Turkey does not need used clothing, household or prescription medicines, blood and blood derivatives, medical or paramedical personnel or teams, field hospitals, and modular medical units. As do any victims of disasters, they want to rebuild with safer houses, have their "normal" health problems attended at the health center, put their children in school, and get back to their lives. Unilateral contributions of unrequested goods are inappropriate, burdensome, and divert resources from what is needed most.

There are lessons to be learned. While it is true that the Turkish authorities were unprepared, who ever is ready for a disaster of this magnitude? The World Health Organization should have done more to strengthen the local capacity, but with what resources? The U.S. and other countries spent millions of dollars to dispatch search and rescue teams - who arrived after the most critical first hours or days - to a country where thousands of local medical doctors volunteered their services. A small part of this money could have been applied more effectively in preparedness and prevention activities.

We need to educate donors just as we need to educate potential victims of disasters. A little preparedness can go a long way toward alleviating the "secondary" disasters often visited on countries. Increased funding for the U.S. Office of Foreign Disaster Assistance for disaster preparedness and prevention in the developing countries and more funding from other bilateral or international agencies could help matters.

If donors would commit now to strengthen the local capacity to respond to future disasters in Turkey, in the disaster-prone countries of the Americas, and other places, and learn what is important and what is futile in helping countries, the world would be better off.
Autbor Note: This article was submitted to the $\mathrm{Op}-\mathrm{Ed}$ page of the New York Times, although it has not been printed. A similar type of Letter to the Editor also was submitted to but not printed by the Washington Post. Both newspapers devoted extensive coverage to the earthquake in Turkey. 